\title{
New phylogenomic data support the monophyly of Lophophorata and an Ectoproct-Phoronid clade and indicate that Polyzoa and Kryptrochozoa are caused by systematic bias
}

Maximilian P Nesnidal ${ }^{1}$, Martin Helmkampf ${ }^{1,2}$, Achim Meyer ${ }^{3}$, Alexander Witek ${ }^{4}$, Iris Bruchhaus ${ }^{5}$, Ingo Ebersberger ${ }^{6}$, Thomas Hankeln ${ }^{4}$, Bernhard Lieb ${ }^{3}$, Torsten H Struck ${ }^{7}$ and Bernhard Hausdorf ${ }^{*^{*}}$

\begin{abstract}
Background: Within the complex metazoan phylogeny, the relationships of the three lophophorate lineages, ectoprocts, brachiopods and phoronids, are particularly elusive. To shed further light on this issue, we present phylogenomic analyses of 196 genes from 58 bilaterian taxa, paying particular attention to the influence of compositional heterogeneity.

Results: The phylogenetic analyses strongly support the monophyly of Lophophorata and a sister-group relationship between Ectoprocta and Phoronida. Our results contrast previous findings based on rDNA sequences and phylogenomic datasets which supported monophyletic Polyzoa (= Bryozoa sensu lato) including Ectoprocta, Entoprocta and Cycliophora, Brachiozoa including Brachiopoda and Phoronida as well as Kryptrochozoa including Brachiopoda, Phoronida and Nemertea, thus rendering Lophophorata polyphyletic. Our attempts to identify the causes for the conflicting results revealed that Polyzoa, Brachiozoa and Kryptrochozoa are supported by character subsets with deviating amino acid compositions, whereas there is no indication for compositional heterogeneity in the character subsets supporting the monophyly of Lophophorata.

Conclusion: Our results indicate that the support for Polyzoa, Brachiozoa and Kryptrochozoa gathered so far is likely an artifact caused by compositional bias. The monophyly of Lophophorata implies that the horseshoe-shaped mesosomal lophophore, the tentacular feeding apparatus of ectoprocts, phoronids and brachiopods is, indeed, a synapomorphy of the lophophorate lineages. The same may apply to radial cleavage. However, among phoronids also spiral cleavage is known. This suggests that the cleavage pattern is highly plastic and has changed several times within lophophorates. The sister group relationship of ectoprocts and phoronids is in accordance with the interpretation of the eversion of a ventral invagination at the beginning of metamorphosis as a common derived feature of these taxa.
\end{abstract}

Keywords: Bryozoa, Brachiopoda, Brachiozoa, Ectoprocta, Lophophorata, Phoronida, Polyzoa, Kryptrochozoa, Compositional bias

\footnotetext{
* Correspondence: hausdorf@zoologie.uni-hamburg.de

'Zoological Museum, University of Hamburg, Martin-Luther-King-Platz 3,

D-20146 Hamburg, Germany

Full list of author information is available at the end of the article
} waiver (http://creativecommons.org/publicdomain/zero/1.0/) applies to the data made available in this article, unless otherwise stated. 


\section{Background}

The evolution of metazoan body plans remains highly controversial due to persisting uncertainty regarding the phylogeny of major animal clades. In this context, the phylogenetic position of the three lophophorate lineages, namely ectoprocts, brachiopods and phoronids, which are mainly marine invertebrates characterized by an eponymous filter apparatus, has proven to be particularly elusive. Based on ontological and morphological data, they were initially considered the sister or, alternatively, the paraphyletic stem-group of Deuterostomia [1-5]. However, molecular phylogenetic analyses changed our views about the relationships of the lophophorate lineages. Based on analyses of $18 \mathrm{~S}$ rDNA sequences, Halanych et al. [6] were the first to recognize that the lophophorate lineages are more closely related to Annelida and Mollusca than to deuterostomes. As a consequence, they united Lophophorata and Trochozoa to form Lophotrochozoa. Since then, the monophyly of Lophotrochozoa has been confirmed by further analyses of rDNA sequences [7-13], single nuclear protein-encoding genes (e.g., [14,15]), Hox genes [16,17], mitochondrial protein sequences [18-24], multiple nuclear protein-encoding sequences $[25,26]$ and by phylogenomic approaches [27-35]. The only potential morphological apomorphy of Lophotrochozoa found so far is a larval apical organ with serotonin expressing flask-shape cells [36,37].

While the monophyly of the Lophotrochozoa has meanwhile been widely accepted, the discussion concerning the phylogenetic relationships within Lophotrochozoa is still ongoing. Halanych et al. [6] suggested that lophophorates are polyphyletic, because ectoprocts formed the sister group of all other lophotrochozoans in their tree. Moreover, they proposed that phoronids are the sister clade of articulate brachiopods, making brachiopods also paraphyletic. It turned out that their clustering of phoronids and articulate brachiopods was an artifact probably caused by a chimeric sequence [38]. Still, the monophyly of Brachiozoa (=Phoronozoa) including brachiopods and phoronids was later independently corroborated by analyses based on rDNA [7,8,12,13,38-41] and sodium-potassium ATPase $\alpha$-subunit sequences [15], multiple nuclear protein-encoding sequences [26,42], total evidence analyses $[9,39,43]$ and phylogenomic approaches $[30,35]$. The relationships within Brachiozoa are, however, in dispute. Whereas some rDNA analyses indicate that brachiopods are paraphyletic and phoronids are the sister group of inarticulate brachiopods $[38,40,41,44]$, brachiopods come out as monophyletic in analyses of morphological data $[2,4,9,39,43,45-47]$, of multiple nuclear protein-encoding sequences [42], and of phylogenomic datasets [30,35].

Furthermore, phylogenomic analyses suggested that phoronids and brachiopods form a clade with nemerteans [28-30,35,48,49], named Kryptrochozoa [48]. Finally, phylogenomic analyses indicated that ectoprocts are the sister group of entoprocts and cycliophorans. As a consequence, the old Polyzoa (=Bryozoa sensu lato) hypothesis was revived [27,28,30-34], which has been supported by a few morphologists [47], and which has recently also been corroborated by analyses of rDNA sequences [12,13], albeit with weak support.

The relationships of Kryptrochozoa and Polyzoa to other lophotrochozoan phyla could, so far, not be decisively resolved. This is despite the fact that numerous EST and genome projects have resulted in an improved taxon sampling and an increase of the number of available genes [27-34]. While phylogenomic studies are likely to reduce the influence of random errors and gene specific influences on phylogenetic inference [50], they cannot cope with the fact that model violations such as compositional biases in the data can confound accurate tree reconstruction [51-53]. That a biased amino acid composition indeed affects phylogenetic analyses of the metazoan phyla has been demonstrated by Nesnidal et al. [35]. Two main strategies have been proposed for dealing with compositional heterogeneity in the data. The most straightforward procedure is the exclusion of particularly affected partitions from the analysis. Alternatively, one can rely on phylogeny reconstruction methods that can account for compositional heterogeneity, and thus ameliorate their confounding influence. The outcome of the tree reconstruction varies with the chosen method to cope with the bias. Whereas some approaches supported the monophyly of Polyzoa including ectoprocts and entoprocts, other strategies, such as the exclusion of taxa with the most deviating amino acid composition surprisingly revealed monophyletic Lophophorata [35].

In this study we investigated the relationships among the lophophorate lineages and other lophotrochozoans together with potential sources of systematic errors that might affect these phylogenetic analyses, namely contaminations, incorrect orthology assignments and compositional bias. We base our analyses on a new dataset comprising 196 proteins from 58 bilaterian taxa.

\section{Results and discussion}

\section{Relationships of the lophophorate lineages}

The complete dataset that we compiled for the phylogenomic analysis of the relationships of the lophophorate lineages comprised 196 genes from 58 metazoan taxa. The corresponding super-alignment spans 41,292 amino acid positions and has $50.4 \%$ data coverage. A PhyloBayes analysis of this dataset with the CAT model (Figure 1) revealed strong support for the monophyly of Lophophorata (Bayesian posterior probability (BPP): 0.99 ) and the monophyly of Ectoprocta + Phoronida (BPP: 0.99). A maximum likelihood analysis with the LG model (Figure 2) confirmed these relationships, albeit without statistical support or 


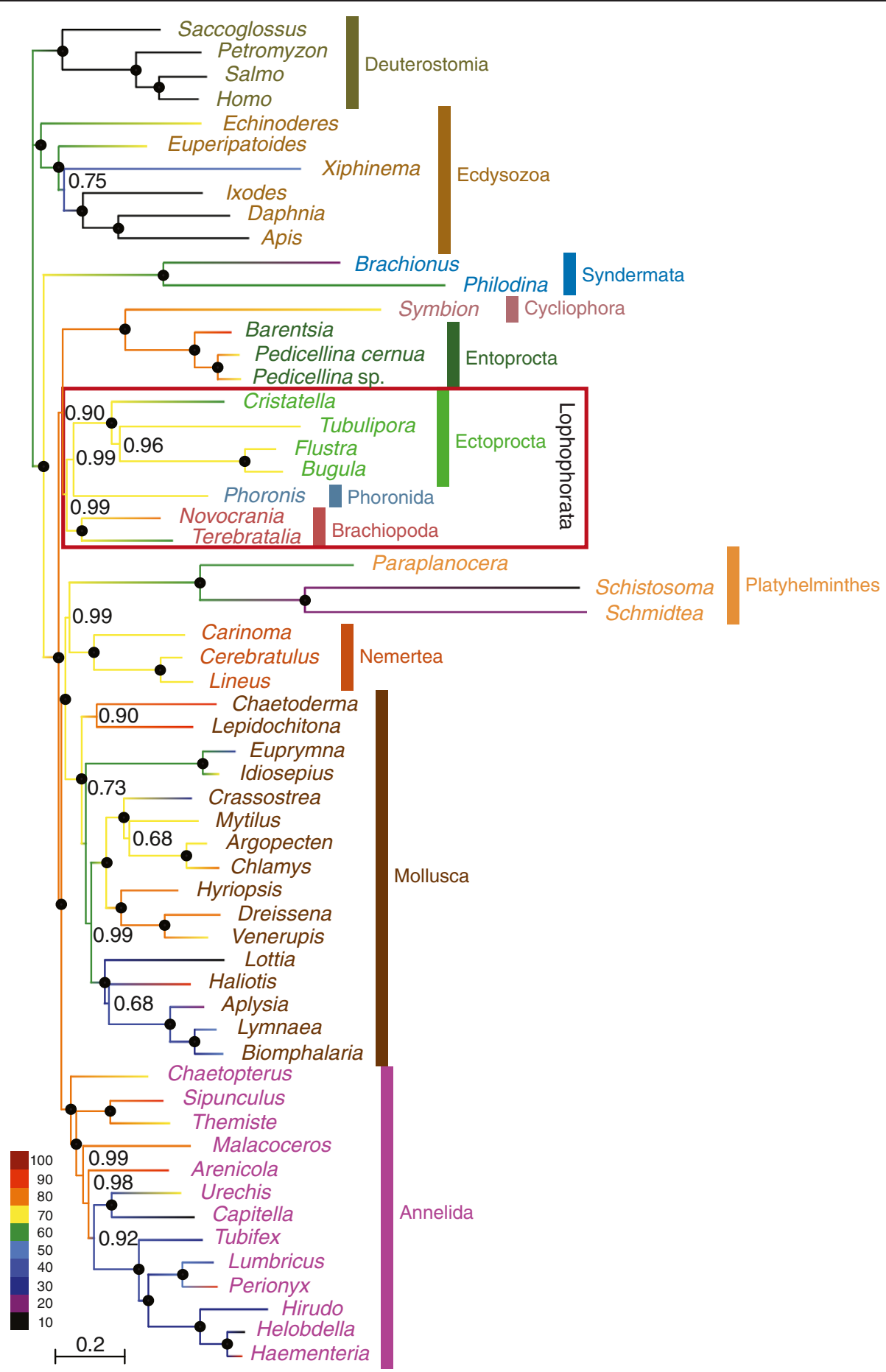

Figure 1 Bayesian inference reconstruction with the CAT model based on 41,292 amino acid positions derived from 196 proteins of 58 taxa. Bayesian posterior probabilities are shown to the right of the nodes; posterior probabilities equal to 1.0 are indicated by black circles. The colour of the branches visualizes the percentage of missing data.

only weak support (bootstrap support (BS) for Lophophorata: 37\%; for Ectoprocta + Phoronida: 55\%). A selection of those positions from the complete dataset where data are available from at least $50 \%$ of all included taxa increased data coverage to $72.4 \%$. The percentage of known character states increased especially in the less well-covered smaller phyla that are the focus of our study (compare the colour coding of the branches in Figures 1 and 2 versus Figures 3 and 4). This can also been seen in density distributions of shared missing data, which is strongly shifted to lower 


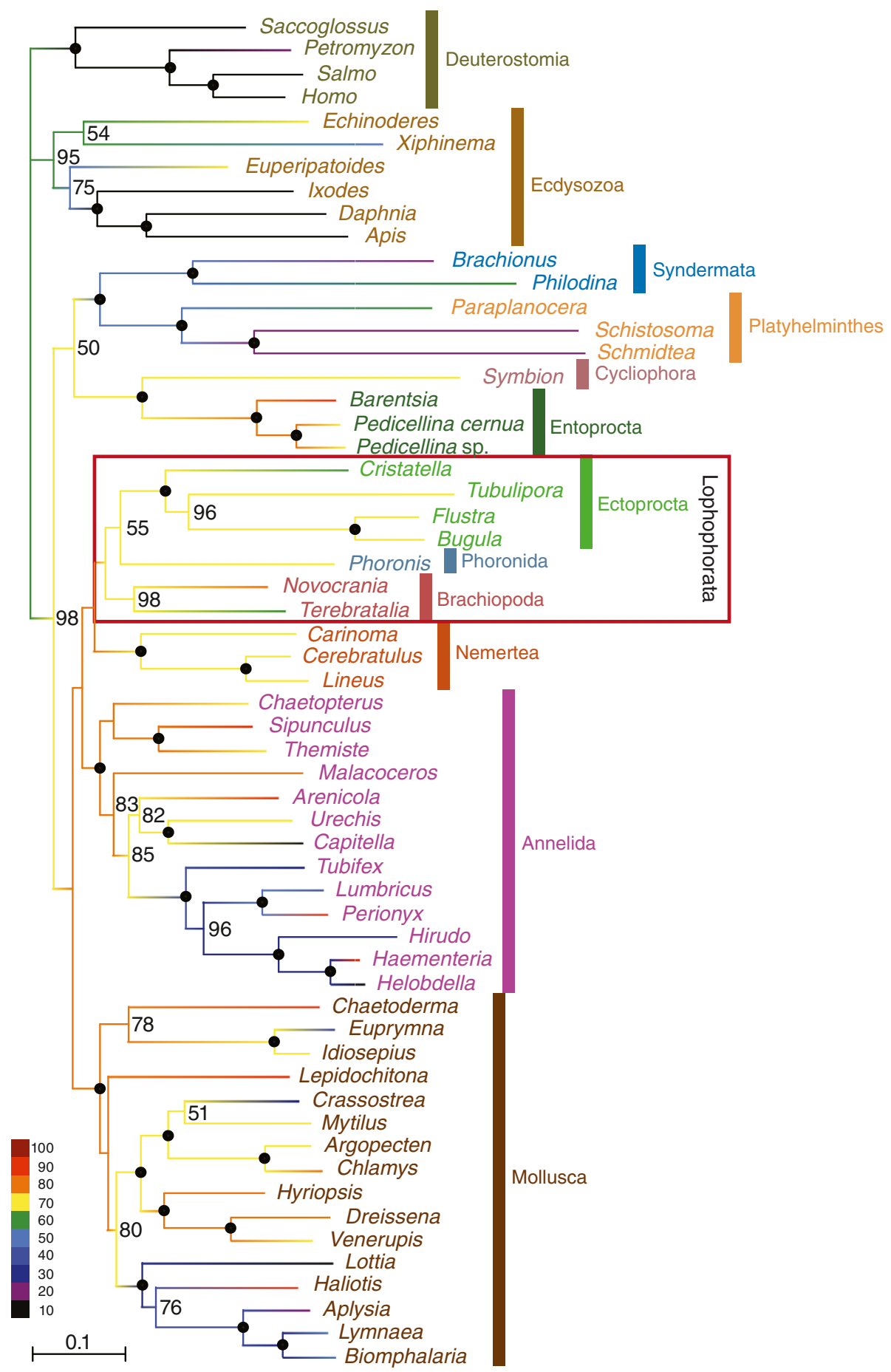

Figure 2 Maximum likelihood tree calculated with the $L G+G+F$ model based on 41,292 amino acid positions derived from 196 proteins of $\mathbf{5 8}$ taxa. Bootstrap values larger than 50\% are shown to the right of the nodes; 100\% bootstrap values are indicated by black circles. The colour of the branches visualizes the percentage of missing data.

values in the reduced dataset (compare Additional file 1: Figure S1 and Additional file 2: Figure S2). Phylogenomic analyses of this dataset encompassing 15,849 sites (Figures 3 and 4) confirmed the monophyly of Lophophorata $\left(\mathrm{BPP}_{\text {red }}\right.$ : $\left.1.00 ; \mathrm{BS}_{\text {red }}: 37 \%\right)$ and the monophyly of Ectoprocta +
Phoronida (BPP $\left.{ }_{\text {red }}: 1.00 ; \mathrm{BS}_{\text {red }}: 57 \%\right)$ and, thus, show that these groupings are not artifacts resulting from the amount of missing data. However, rather than based solely on the amount of missing data artificial signal for a grouping of taxa might also stem from a strong degree of overlap 


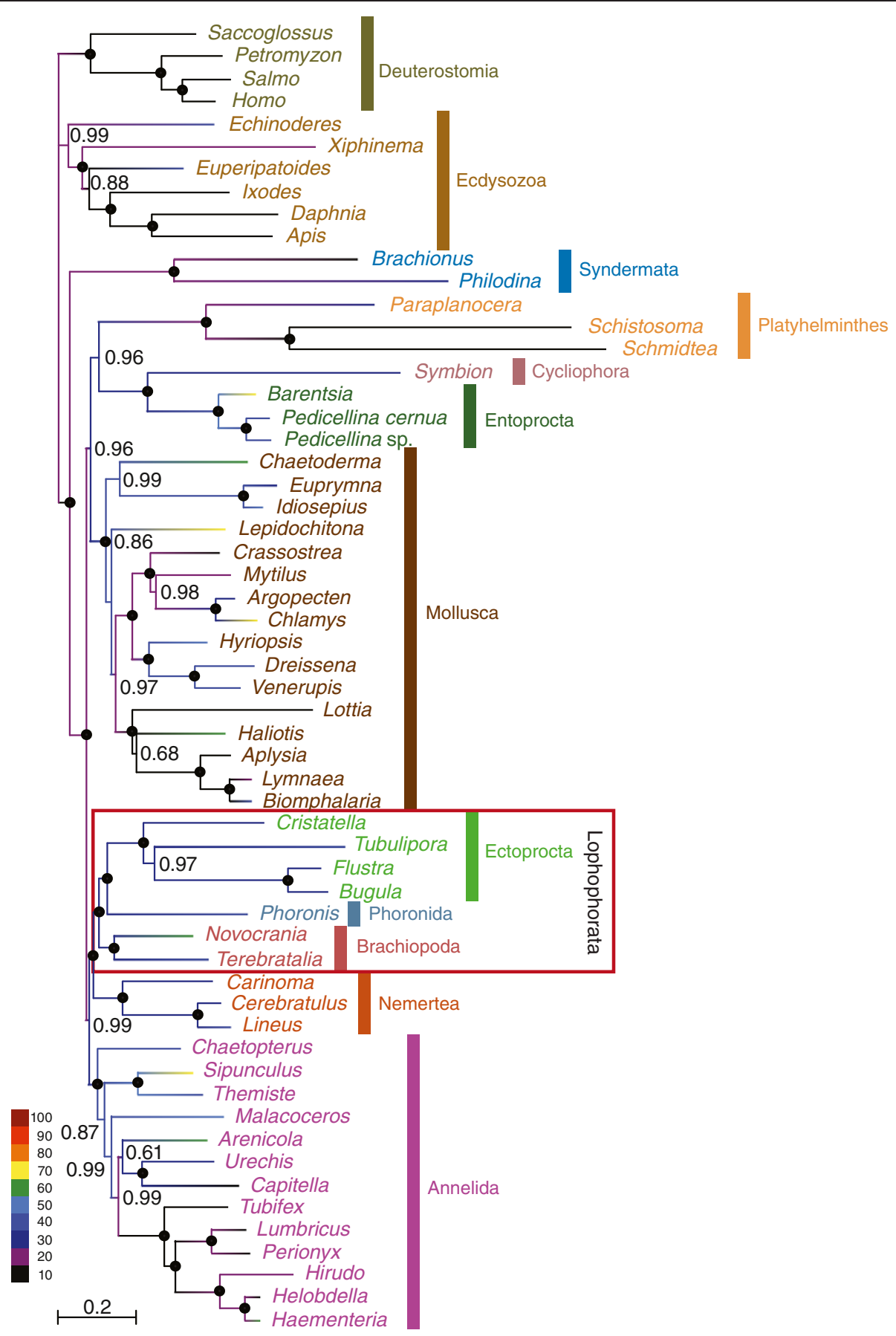

Figure 3 Bayesian inference reconstruction with the CAT model based on 15,849 amino acid positions of 58 taxa. Bayesian posterior probabilities are shown to the right of the nodes; posterior probabilities equal to 1.0 are indicated by black circles. The colour of the branches visualizes the percentage of missing data.

in missing data shared between taxa, if the missing data are not randomly distributed across the taxa, but are systematically biased [54-56]. Hierarchical clustering analyses based on the degree of overlap in missing data shared between taxa (Additional file 1: Figure S1 and Additional file 2: Figure S2) corroborate that neither Lophophorata nor
Ectoprocta + Phoronida are artifacts caused by shared missing data. The taxa belonging to these groups do not cluster in these analyses, but are scattered among other lophotrochozoan taxa.

These results challenge the Brachiozoa, Polyzoa (=Bryozoa sensu lato) as well as Kryptrochozoa hypotheses. 


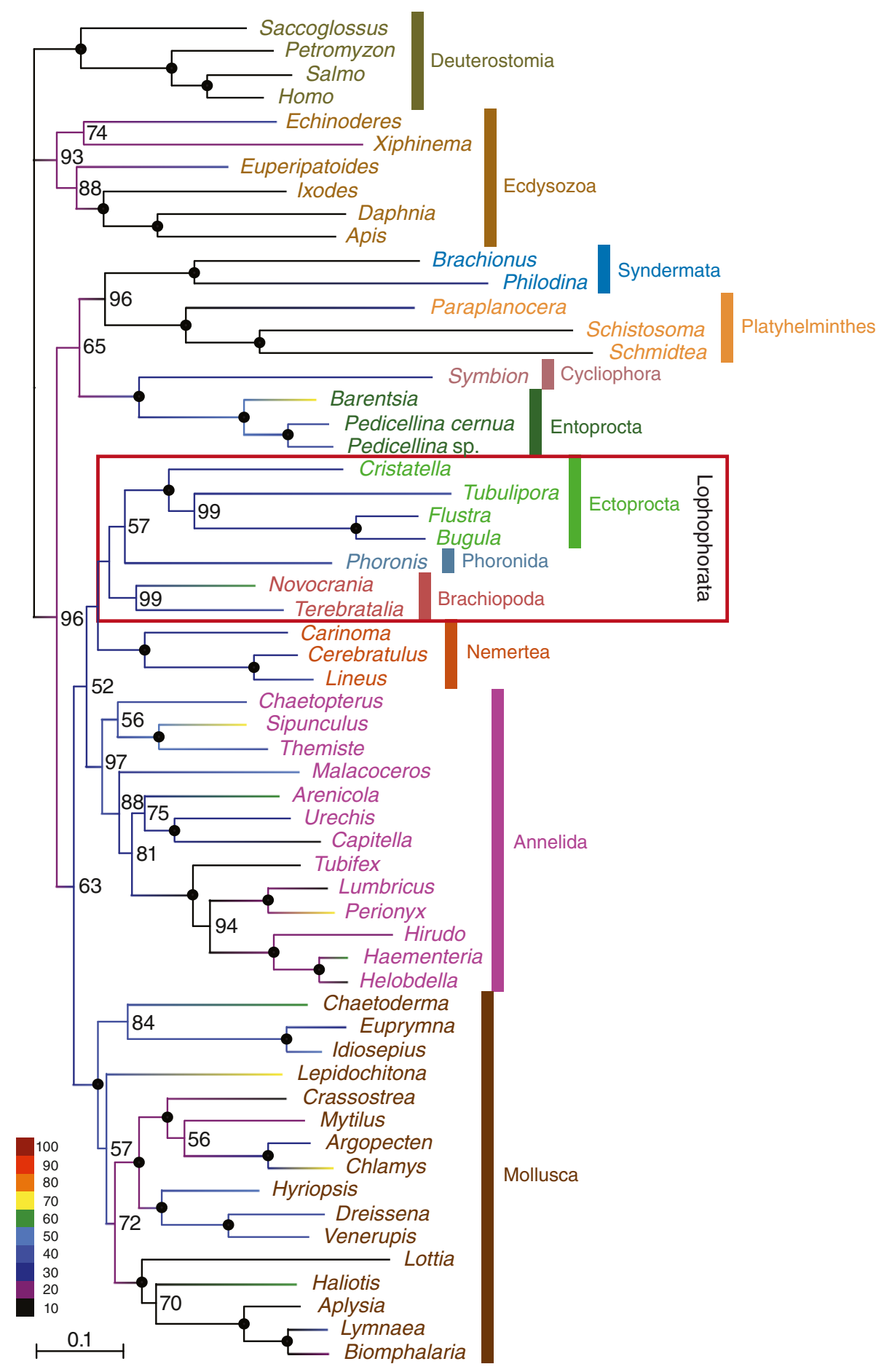

Figure 4 Maximum likelihood tree calculated with the LG+G+F model based on 15,849 amino acid positions of 58 taxa. Bootstrap values larger than $50 \%$ are shown to the right of the nodes; $100 \%$ bootstrap values are indicated by black circles. The colour of the branches visualizes the percentage of missing data.

Interestingly, a sister group relation between ectoprocts and phoronids had been previously proposed based on morphological data [57,58]. The PhyloBayes analysis with the reduced dataset (Figure 3) and the maximum likelihood analyses support a sister group relationship between Lophophorata and Nemertea (BPP: 1.00; BS: $38 \%$; $\left.\mathrm{BS}_{\text {red }}: 46 \%\right)$. In contrast, the PhyloBayes analysis with the complete dataset (Figure 1) indicates that 
Entoprocta + Cycliophora might be the sister group of Lophophorata (BPP: 0.90) and that Nemertea and Platyhelminthes are sister groups (BPP: 0.99) as has previously been suggested based on morphological data ('Parenchymia' hypothesis [4,47], but see [31]).

\section{Causes of incongruent topologies}

The results of our phylogenetic analyses are incongruent with those of previous phylogenomic analyses, which revealed monophyletic Polyzoa [27,30-35], Brachiozoa [30,35] and Kryptrochozoa [28-30,35,48,49]. These incongruences cannot be ascribed to random errors, since the monophyly of Polyzoa, Brachiozoa and Kryptrochozoa was strongly supported in most of the previous phylogenomic analyses, whereas the mutually exclusive monophyly of Lophophorata and Ectoprocta + Phoronida is strongly supported in the PhyloBayes analyses with the CAT model (Figures 1, 3). The hierarchical clustering analyses based on degrees of overlap in missing data shared between taxa (Additional file 1: Figure S1 and Additional file 2: Figure S2) also showed that similar to Lophophorata and Ectoprocta + Phoronida Polyzoa, Brachiozoa and Kryptrochozoa cannot be attributed to shared missing data as the taxa belonging to these groups are scattered throughout the tree and do not cluster. Therefore, we checked whether these incongruences might be caused by contaminations, incorrect orthology assignments or by compositional bias.

We investigated the possibility that contaminations or a few paralogs in the sequence data affect the topology with respect to our focal groups. In this instance we would expect that apomorphies of Lophophorata, as determined by a parsimony mapping of the data on the maximum likelihood tree, cluster in only small parts of the alignment. However, Figure 5A shows convincingly that the apomorphies are distributed evenly along the whole alignment. Thus, the support for Lophophorata is not the result of a few contaminations or incorrect orthology assignments. The same holds for the positions supporting the Ectoprocta + Phoronida clade (Figure 5B) as well as for those that support Polyzoa (Figure 5C), Brachiozoa (Figure 5D) and Kryptrochozoa (Figure 5E) in trees in which these groups are constrained to be monophyletic.

As a first step to assess whether a compositional bias might have affected a phylogenomic analysis as asserted by Nesnidal et al. [35], we visualized similarities in the amino acid composition of the focal taxa in non-metric multidimensional scalings. A non-metric multidimensional scaling based on the ribosomal protein dataset of Nesnidal et al. [35] (Figure 6A) shows that the space occupied by the ectoproct sequences overlaps with that occupied by the entoproct sequences, but is clearly separated from that occupied by phoronids, brachiopod and nemertean sequences. In contrast, the space occupied by the ectoproct sequences in the non-metric multidimensional scaling based on the new dataset (Figure 6B) does not overlap with that occupied by entoprocts. These analyses indicate that the Polyzoa clade in the former analyses might have been an artifact resulting from compositional bias.

We investigated this issue further by analyzing the amino acid composition of the character subsets that support the conflicting nodes. The amino acid composition of the reconstructed ancestral sequence of Lophophorata based on the new dataset is not significantly deviating from the overall amino acid composition in the dataset including the 1,005 characters that display apomorphies for Lophophorata (Table 1). The same is true for the ancestral sequence of Lophophorata + Nemertea. Thus, this analysis provides no indication that the monophyly of Lophophorata is caused by a compositional bias. However, the composition of the reconstructed ancestral amino acid sequence of Ectoprocta + Phoronida is significantly deviating from the overall amino acid composition in the dataset including the 1,271 characters that display apomorphies for Ectoprocta + Phoronida (Table 1).

To investigate the so far hidden support in our new data for the Polyzoa, Brachiozoa and Kryptrochozoa hypotheses respectively, we constructed maximum likelihood trees enforcing the monophyly of these groups. We then

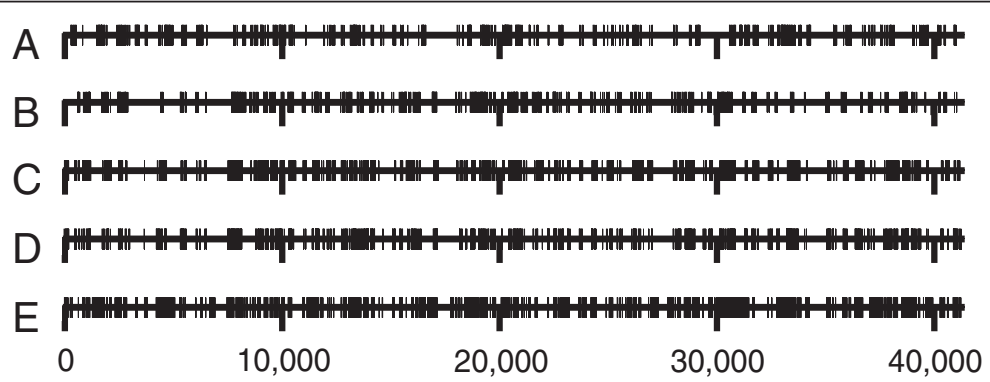

Figure 5 Distribution of autapomorphies for different taxa across the concatenated alignment. (A) Lophophorata, (B) Ectoprocta + Phoronida, (C) Polyzoa, (D) Brachiozoa, (E) Kryptrochozoa. 

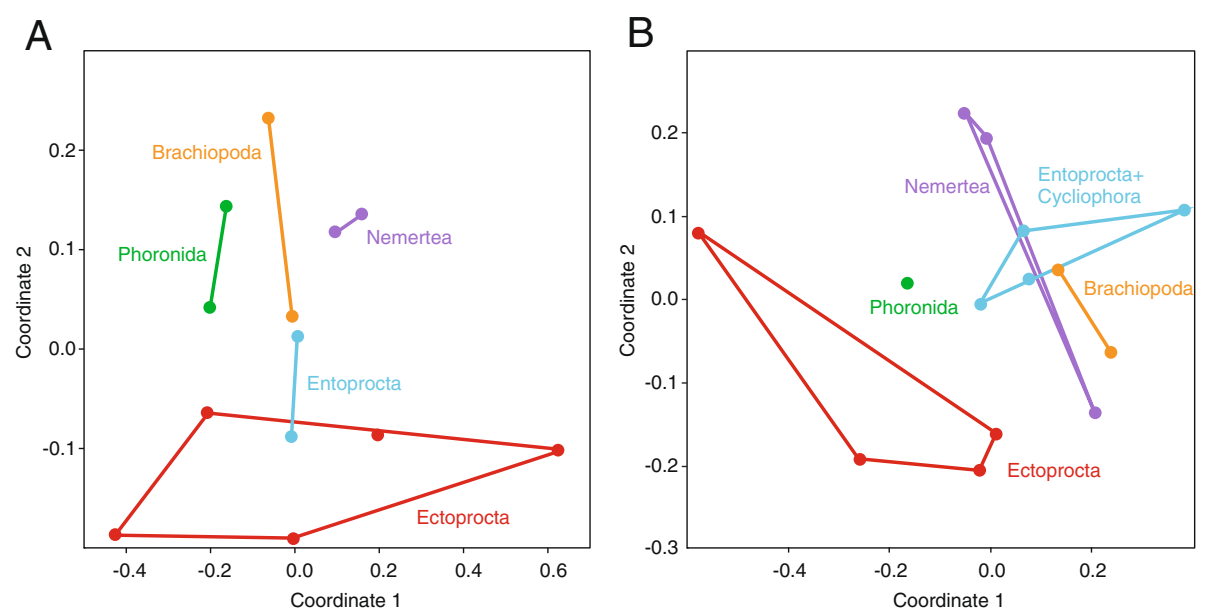

Figure 6 Non-metric multidimensional scalings of compositional distances between amino acid sequences. Scaling of distances between focal taxa using (A) the ribosomal protein dataset of Nesnidal et al. [35] and (B) the dataset used in this study.

repeated the parsimony mapping and investigated the composition of the apomorphies in supporting these groupings. Polyzoa are supported by 1,569 autapomorphies. The amino acid composition of the reconstructed states of the hypothetical polyzoan ancestor for these positions deviates significantly from the overall composition of all taxa at these positions (Table 1). In contrast, the composition of the reconstructed states of the hypothetical

Table 1 Composition of the subsets of characters supporting Lophophorata and Ectoprocta + Phoronida in the unconstrained tree and Brachiozoa and Polyzoa in constrained trees

\begin{tabular}{|c|c|c|}
\hline Hypothesis & $\begin{array}{c}\text { No. of } \\
\text { autapomorphies }\end{array}$ & $\begin{array}{c}\mathrm{p} \text {-value chi-square } \\
\text { test }\end{array}$ \\
\hline Lophophorata & 1,005 & \\
\hline Lophophorata & & $82.54 \%$ \\
\hline $\begin{array}{l}\text { Lophophorata + } \\
\text { Nemertea }\end{array}$ & & $89.02 \%$ \\
\hline Ectoprocta + Phoronida & 1,271 & \\
\hline $\begin{array}{l}\text { Ectoprocta + } \\
\text { Phoronida }\end{array}$ & & $0.01 \% *$ \\
\hline Lophophorata & & $29.57 \%$ \\
\hline Polyzoa & 1,569 & \\
\hline Polyzoa & & $0.29 \% *$ \\
\hline Polyzoa + Brachiozoa & & $31.24 \%$ \\
\hline Brachiozoa & 1,522 & \\
\hline Brachiozoa & & $0.00 \% *$ \\
\hline Lophophorata & & $8.81 \%$ \\
\hline Kryptrochozoa & 1,792 & \\
\hline Kryptrochozoa & & $0.00 \% *$ \\
\hline $\begin{array}{l}\text { Kryptrochozoa + } \\
\text { Annelida }\end{array}$ & & $16.21 \%$ \\
\hline
\end{tabular}

*compositional homogeneity significantly rejected. ancestor of Polyzoa and Brachiozoa, the sister group of Polyzoa in the constrained maximum likelihood tree, for this character subset is not significantly deviating (Table 1). This reveals that the amino acid composition of the characters displaying potential autapomorphies for Polyzoa has changed at the base of Polyzoa. In other words, Ectoprocta and Entoprocta + Cycliophora cluster because of character states that differ from those of other taxa in composition and, as a consequence, Polyzoa might be an artifact resulting from compositional bias.

Similarly, Brachiozoa, a clade comprising Brachiopoda and Phoronida, can be attributed to compositional biases. If we constrain the monophyly of Brachiozoa, they are supported by 1,522 autapomorphies. As for Polyzoa, the amino acid composition of the reconstructed ancestral sequence of Brachiozoa is significantly deviating at the positions that display autapomorphies for Brachiozoa (Table 1), whereas the composition of the reconstructed ancestral sequence of Brachiozoa and Ectoprocta, the sister group of Brachiozoa in the constrained maximum likelihood tree, is not significantly different (Table 1).

The same is true for Kryptrochozoa including Brachiopoda, Phoronida and Nemertea. Kryptrochozoa are supported by 1,792 autapomorphies in a tree in which their monophyly is enforced. The amino acid composition of the reconstructed ancestral sequence of Kryptrochozoa is significantly deviating at the positions that display autapomorphies for this clade (Table 1), whereas the composition of the reconstructed ancestral sequence of Kryptrochozoa and Annelida, the sister group of Kryptrochozoa in the constrained maximum likelihood tree, is not significantly different (Table 1).

The fact that the amino acid composition of a character subset changes at a given node does not necessarily mean that it is an artifactual node. However, in the case 
of the lophophorate lineages, it is more likely that they actually form a monophyletic clade rather than that the conflicting Polyzoa and Kryptrochozoa hypotheses are correct, as we have identified a possible source of systematic error in the data for the latter two hypotheses, but not for the Lophophorata hypothesis. Systematic error resulting from compositional bias might also be the cause of the conflict between the Ectoprocta + Phoronida versus the Brachiozoa hypothesis. However, in this case, both alternatives are potentially affected by compositional bias (Table 1) so that the test for compositional bias does not give a hint which hypothesis corresponds to the true phylogeny.

\section{Implications for the evolution of morphology}

The support for the monophyly of Lophophorata (Figures 1, $2,3,4$ ) indicates that the horseshoe-shaped mesosomal lophophore, the ciliated, tentacular feeding apparatus of ectoprocts, phoronids and brachiopods, is homologous, despite some differences in the structure between these groups [47]. Our results suggest that the epistome, a muscular lobe that is used to push the infiltrated particles into the mouth opening, is a further innovation of the lophophorate lineage [58].

The position of the lophophorates within Lophotrochozoa renders it unlikely that the lophophore of Lophophorata is homologous with the similar tentacular feeding apparatus of the deuterostome Pterobranchia, with which it has been homologized formerly $[1,2,47]$. Such a homology would require the assumption of multiple, independent transitions from a sessile, filter feeding life style to a mobile life style and associated multiple losses of the tentacular feeding apparatus. However, a sister group relationship between Lophophorata and Entoprocta + Cycliophora as moderately supported by the PhyloBayes analysis with the complete dataset (Figure 1) would imply that a tentacular apparatus for filter feeding as an adaptation to a sessile life style is a synapomorphy of these groups, despite the functional differences between the lophophore of Lophophorata and the tentacular apparatus of Entoprocta [47]. The monophyly of the sessile lophotrochozoan groups with a tentacular feeding apparatus would be much more plausible from a morphological point of view than the Kryptrochozoa hypothesis [28-30,35,48,49] grouping the predatory, vagile nemerteans with the sessile filter feeding brachiopods and phoronids, which have no morphological features in common with nemerteans. However, the conflicting results of our analyses (Figures 1, $2,3,4$ ) indicate that more data are necessary to resolve the interrelationships of Lophophorata, Entoprocta + Cycliophora and Nemertea robustly.

Radial cleavage was formerly considered a symplesiomorphy of lophophorates and deuterostomes [1,2].
However, there are no doubts about the homology of the spiral cleavage of entoprocts, nemerteans, platyhelminths, annelids, and molluscs, the closest relatives of Lophophorata (Figures 1,2,3,4). Taking our phylogeny at face value, parsimony would suggest that radial cleavage evolved secondarily in the lineage leading to the Lophophorata. Alternatively one might assume that Lophophorata is the sister group of the lophotrochozoan phyla that share spiral cleavage. However, the finding that cleavage is spiral in at least some phoronids $[59,60]$ shows how variable cleavage patterns are and that the radial cleavage of lophophorates is probably secondarily derived from spiral cleavage.

Our trees showing a close relationship of Ectoprocta and Phoronida imply that the eversion of a ventral invagination (the metasomal tube in phoronids and the ventral sac in some ectoprocts) at the beginning of the metamorphosis $[3,52,61,62]$ and the loss of setae [61] might be synapomorphies of ectoprocts and phoronids.

Phoronida and Phylactolaemata (Ectoprocta) share a bodywall musculature consisting of a regular grid of an outer layer of circular and an inner layer of longitudinal musculature, whereas Gymnolaemata (=Stenolaemata + Ctenostomata + Cheilostomata), the sister group of Phylactolaemata $[2,28,63]$, and Brachiopoda lack such a distinct regular bodywall musculature [64]. Schwaha and Wanninger [64] discussed whether the similarity of the bodywall musculature of Phoronida and Phylactolaemata evolved convergently or whether Ectoprocta and Phoronida are closely related. Our results support the latter hypothesis. However, a similar bodywall musculature is also found in several other vermiform lophotrochozoan phyla. Thus, it is probably not a synapomorphy for Ectoprocta and Phoronida, but a symplesiomorphy that was lost in Gymnolaemata and Brachiopoda as a result of the evolution of solid exoskeletons.

\section{Conclusions}

Our results support the monophyly of Lophophorata and an ectoproct-phoronid clade and indicate that the support for Kryptotrochozoa and Polyzoa gathered so far is likely an artifact caused by compositional bias. The monophyly of Lophophorata implies that the horseshoeshaped mesosomal lophophore, the tentacular feeding apparatus of ectoprocts, phoronids and brachiopods is a synapomorphy of the lophophorate lineages. The same may apply to radial cleavage. However, among phoronids also spiral cleavage is known. This suggests that the cleavage pattern is highly plastic and has changed several times within lophophorates. The sister group relationship of ectoprocts and phoronids is in accordance with the interpretation of the eversion of a ventral invagination at the beginning of metamorphosis as a common derived feature of these taxa. 


\section{Methods}

\section{Data sources and orthology assignment}

Data were extracted from so far only partly published EST datasets of Tubulipora sp. (Ectoprocta), Flustra foliacea (Ectoprocta), Novocrania anomala (Brachiopoda), Phoronis muelleri (Phoronida), Barentsia elongata (Entoprocta), Lineus viridis (Nemertea) and Brachionus plicatilis (Monogononta), of which only the ribosomal protein encoding sequences had yet been used for phylogenetic studies [27,28,30-33]. The EST data used in our analyses have been deposited in the NCBI EST database [65] under accession numbers LIBEST_025704 (Tubulipora sp.), LIBEST_028288 (Flustra foliacea), LIBEST_028289 (Novocrania anomala), LIBEST_028290 (Phoronis muelleri), LIBEST_026421 (Brachionus plicatilis), LIBEST_027828 (Barentsia elongata) and LIBEST_028316 (Lineus viridis).

The dataset for tree reconstruction was compiled in a two-step procedure. For the initial ortholog search, we first defined a set of seven species with completely sequenced genomes, the so-called primer taxa: Caenorhabditis elegans (Nematoda), Daphnia pulex (Crustacea), Apis mellifera (Insecta), Schistosoma mansoni (Platyhelminthes), Capitella capitata (Annelida), Helobdella robusta (Annelida) and Lottia gigantea (Mollusca). We then used InParanoid-TC [66] to identify genes for which an ortholog was present in each of the seven primer taxa. Finally, we extended the resulting 1,297 ortholog groups (listed in Additional file 1: Figure S1) with sequences from further taxa using HaMStR [66].

\section{Alignment, alignment masking and gene selection}

The amino acid sequences of the 1,297 individual ortholog groups of 58 species were aligned with MAFFT using the most accurate option L-INS-i $[67,68]$. To increase the signal-to-noise ratio, sections with random sequence similarity were identified with ALISCORE version 1.0 [69,70] and subsequently excluded with ALICUT [71]. We constructed individual trees for each protein using a parallel Pthreads-based version of RAxML version 7.7.1 [72,73] with the $\mathrm{LG}+\mathrm{G}+\mathrm{F}$ model [74] to check for unusual topologies and long branches that might indicate hidden paralogy and contaminations. One gene tree shows a very long, highly supported branch separating a clade including Deuterostomia and Ecdysozoa, into which the three nemertean representatives were nested. This topology is inconsistent with the position of Nemertea within Lophotrochozoa inferred in other analyses and our own analyses, if this protein is excluded. This topology indicates probably a paralogy [75,76]. Thus, we excluded this protein. We also inspected each protein alignment manually for contaminant sequences and poorly conserved motives. Problematic sequences that are difficult to align or result in extraordinarily long branches were excluded from the individual unmasked alignments and all single protein datasets were re-aligned with MAFFT and masked using ALISCORE. All masked alignments that were at least 100 amino acids long and contained at least 25 taxa after the various preprocessing and filtering steps were subsequently concatenated. To assess the effect of missing data, we constructed a reduced alignment by selecting those positions from the basic alignment at which data are available from at least $50 \%$ of all included taxa using MEGA version 5.1 [77]. Both superalignments have been deposited at TreeBASE ([78], accession number S13700).

\section{Phylogenetic analyses}

We performed Bayesian inference analyses with the CAT model that adjusts for site-specific amino acid frequencies $[79,80]$ as implemented in PhyloBayes MPI version 1.4f (http://megasun.bch.umontreal.ca/People/ lartillot/www/index.htm). For each of the two datsets (complete and reduced) two independent chains were run for 27,500 or 30,000 points, respectively, of which 15,000 or 20,000 were discarded as burn-in. The largest discrepancy observed across all bipartitions (maxdiff) was 0.10 or 0.13 , respectively. Taking every 10 th sampled tree, a 50\%-majority rule consensus tree was computed using both chains of a dataset.

We performed maximum likelihood analyses using a parallel Pthreads-based version of RAxML version 7.7.1 [72,73] with the LG+G+F model [74]. We computed 10 maximum likelihood trees using 10 distinct randomized maximum parsimony starting trees and chose the tree with the highest likelihood. Rapid bootstrapping [81] was used to assess the statistical branch support in the reconstructed phylogeny. We conducted rapid bootstrap analysis and searched for the best-scoring maximum likelihood tree in one single program run. The number of necessary replicates was inferred using the extended majority-rule consensus tree criterion ([82]; 250 replications inferred using the option autoMRE in RAxML).

\section{Influence of missing data on phylogenetic reconstruction}

We visualized the level of missing data in the phylogenetic trees as suggested by Roure et al. [83]. To infer whether the "ancestral" state of a given position for a given node is unknown or known, sequences were recoded with 0's and 1's depending on each character state being present or absent. Ancestral sequences were reconstructed by maximum parsimony, using PAUP* version 4.0 beta 10 [84] with the ACCTRAN option, based on the topologies inferred as described above. The percentage of missing data was displayed in the trees by colour coding the branches.

Furthermore, we investigated the influence of shared missing data on phylogenetic reconstruction by hierarchical clustering analyses based on the degree of 
overlap in missing data between taxa using $\mathrm{BaCoCa}$ version 1.105 [85].

\section{Non-metrical multidimensional scaling of amino acid composition}

We visualized similarities in the amino acid composition of the focal taxa in a non-metric multidimensional scaling as implemented in PAST version 2.17c [86] based on compositional distances (one half the sum of squared difference in counts of residues) between taxa calculated with MEGA version 5.1 [77].

\section{Node based evaluation of potential compositional bias} To investigate whether a node might be affected by compositional bias we determined whether there was a significant shift in the amino acid composition of the apomorphies of this node between the last common ancestor of the clade in question and its direct ancestor. Amino acid substitutions along the tree were traced by parsimony mapping using PAUP* [84]. We retrieved all positions from the dataset, which showed an apomorphy for a specified node. If the node corresponding to the hypothesis to be tested was not present in the unconstrained maximum likelihood tree, we calculated a tree in which the group of interest was constrained to be monophyletic. In addition to the terminal taxa we also included the reconstructed ancestral state of the node in question as well as of the direct ancestor of this node in these subsets. For example, the test for an artificial attraction of Ectoprocta and Phoronida due to a deviating amino acid composition is based on a subset of the alignment comprising the character states at all positions where the ancestor of the Ectoprocta + Phoronida clade is characterized by apomorphies. All terminal taxa and the reconstructed states of the last common ancestor of Ectoprocta and Phoronida as well as its direct ancestor, that is the last common ancestor of all Lophophorata, were considered. Compositional heterogeneity in the alignment subsets was investigated using a chi-square test implemented in TREE-PUZZLE version 5.2 [87].

\section{Additional files}

Additional file 1: Figure S1. Heat map analysis combined with hierarchical clustering of complete dataset of the degree of overlap in missing data shared between taxa. The order of the taxa from left to right along the $x$-axis is the same as from bottom to top along the $y$-axis. The higher taxonomic unit of each species is highlighted as indicated in the legend on top. Colours in the heat map indicate proportion of shared missing data ranging from 0 (orange) to 0.8 (red) (see key in upper left corner). The density distribution of the proportions is given in the upper left corner.

Additional file 2: Figure S2. Heat map analysis combined with hierarchical clustering of reduced dataset of the degree of overlap in missing data shared between taxa. The order of the taxa from left to right along the $x$-axis is the same as from bottom to top along the $y$-axis.
The higher taxonomic unit of each species is highlighted as indicated in the legend on top. Colours in the heat map indicate proportion of shared missing data ranging from 0 (orange) to 0.5 (red) (see key in upper left corner). The density distribution of the proportions is given in the upper left corner.

Competing interests

The authors declare that they have no competing interests.

\section{Authors' contributions}

$\mathrm{MH}, \mathrm{AM}, \mathrm{AW}, \mathrm{IB}, \mathrm{TH}, \mathrm{BL}$ and THS generated and provided EST sequences. IE compiled and aligned the ortholog groups. MPN and $\mathrm{BH}$ performed the phylogenetic analyses. $\mathrm{BH}$ designed the study and drafted the manuscript. All authors contributed to, read and approved the final manuscript.

\section{Acknowledgments}

We are grateful to Michael Kube and Richard Reinhardt (Max Planck Institute for Molecular Genetics, Berlin) for the construction and sequencing of CDNA libraries and to Erik Sperling and three anonymous reviewers for constructive remarks on an earlier version of this paper. This study was funded by the priority program "Deep Metazoan Phylogeny" of the Deutsche

Forschungsgemeinschaft (grants HA 2103/4 to TH; HA 2763/5 to BH and IB; Li 998/3 to BL; STR 683/5 and STR 683/8 to THS). TH acknowledges additional funding by the University of Mainz Center for Computational Sciences (SRFN).

\section{Author details}

'Zoological Museum, University of Hamburg, Martin-Luther-King-Platz 3, D-20146 Hamburg, Germany. ${ }^{2}$ School of Life Sciences, Arizona State University, 427 East Tyler Mall, Tempe, AZ 85287, USA. ${ }^{3}$ Institute of Zoology, Johannes Gutenberg University, J-J Becher-Weg 7, D-55128 Mainz, Germany. ${ }^{4}$ Institute of Molecular Genetics, Biosafety Research and Consulting, Johannes Gutenberg University, J-J Becherweg 32, D-55099 Mainz, Germany. ${ }^{5}$ Bernhard Nocht Institute for Tropical Medicine, Bernhard-Nocht-Str 74, D-20359 Hamburg, Germany. ${ }^{6}$ Department for Applied Bioinformatics, Institute for Cell Biology and Neuroscience, Goethe University, Max-von-Laue-Str 13, D-60438 Frankfurt, Germany. ${ }^{7}$ Zoologisches Forschungsmuseum Alexander Koenig, Adenauerallee 160, D-53113 Bonn, Germany.

Received: 9 September 2013 Accepted: 7 November 2013

Published: 17 November 2013

\section{References}

1. Ax P: Basic phylogenetic systematization of the Metazoa. In The hierarchy of life. Edited by Fernholm B, Bremer K, Jornvall H. Amsterdam: Elsevier; 1989:229-245

2. Ax P: Das System der Metazoa III. Heidelberg: Spektrum Akademischer Verlag; 2001

3. Lüter C, Bartolomaeus T: The phylogenetic position of Brachiopoda-a comparison of morphological and molecular data. Zool Scripta 1997, 26:245-254.

4. Sørensen MV, Funch P, Willerslev E, Hansen AJ, Olesen J: On the phylogeny of the Metazoa in the light of Cycliophora and Micrognathozoa. Zool Anz 2000, 239:297-318.

5. Brusca RC, Brusca GJ: Invertebrates. 2nd edition. Sunderland, MA: Sinauer Associates; 2003.

6. Halanych KM, Bacheller JD, Aguinaldo AA, Liva SM, Hillis DM, Lake JA: Evidence from $18 \mathrm{~S}$ ribosomal DNA that the Lophophorates are protostome animals. Science 1995, 267:1641-1642

7. Mackey LY, Winnepenninckx B, De Wachter R, Backeljau T, Emschermann P, Garey JR: 18S rRNA suggests that Entoprocta are protostomes, unrelated to Ectoprocta. J Mol Evol 1996, 42:552-559.

8. Littlewood DTJ, Telford MJ, Clough KA, Rohde K: Gnathostomulida-an enigmatic metazoan phylum from both morphological and molecular perspective. Mol Phylogenet Evol 1998, 9:72-79.

9. Peterson KJ, Eernisse DJ: Animal phylogeny and the ancestry of bilaterians: inferences from morphology and 18S rDNA gene sequences. Evol Dev 2001, 3:170-205. 
10. Mallatt J, Winchell CJ: Testing the new animal phylogeny: first use of combined large-subunit and small-subunit rRNA gene sequences to classify the protostomes. Mol Biol Evol 2002, 19:289-301.

11. Passamaneck $Y$, Halanych KM: Lophotrochozoan phylogeny assessed with LSU and SSU data: evidence of lophophorate polyphyly. Mol Phylogenet Evol 2006, 40:20-28.

12. Paps J, Baguñà J, Riutort M: Lophotrochozoa internal phylogeny: new insights from an up-to-date analysis of nuclear ribosomal genes. Proc $R$ Soc London B 2009, 276:1245-1254.

13. Mallatt J, Craig CW, Yoder MJ: Nearly complete rRNA genes assembled from across the metazoan animals: effects of more taxa, a structure-based alignment, and paired-sites evolutionary models on phylogeny reconstruction. Mol Phylogenet Evol 2010, 55:1-17.

14. Ruiz-Trillo I, Paps J, Loukota M, Ribera C, Jondelius U, Baguñà J, Riutort M: A phylogenetic analysis of myosin heavy chain type II sequences corroborates that Acoela and Nemertodermatida are basal bilaterians. Proc Natl Acad Sci USA 2002, 99:11246-11251.

15. Anderson FE, Cordoba AJ, Thollesson M: Bilaterian phylogeny based on analyses of a region of the sodium-potassium ATPase a-subunit gene. J Mol Evol 2004, 58:252-268.

16. De Rosa R, Grenier JK, Andreeva T, Cook CE, Adoutte A, Akam M, Carroll SB, Balavoine G: Hox genes in brachiopods and priapulids and protostome evolution. Nature 1999, 399:772-776.

17. Passamaneck YJ, Halanych KM: Evidence from Hox genes that bryozoans are lophotrochozoans. Evol Dev 2004, 6:275-281.

18. Stechmann A, Schlegel M: Analysis of the complete mitochondrial DNA sequence of the brachiopod Terebratulina retusa places Brachiopoda within the protostomes. Proc R Soc Lond B 1999, 266:2043-2052.

19. Helfenbein $K G$, Boore $\mathrm{L}$ : The mitochondrial genome of Phoronis architecta-comparisons demonstrate that phoronids are lophotrochozoan protostomes. Mol Biol Evol 2004, 21:153-157.

20. Waeschenbach A, Telford MJ, Porter JS, Littlewood DTJ: The complete mitochondrial genome of Flustrellidra hispida and the phylogenetic position of Bryozoa among the Metazoa. Mol Phylogenet Evol 2006, 40:195-207.

21. Jang $\mathrm{KH}$, Hwang UW: Complete mitochondrial genome of Bugula neritina (Bryozoa, Gymnolaemata, Cheilostomata): phylogenetic position of Bryozoa and phylogeny of lophophorates within the Lophotrochozoa. BMC Genomics 2009, 10:167.

22. Sun M, Wu Z, Shen X, Ren J, Liu X, Liu H, Liu B: The complete mitochondrial genome of Watersipora subtorquata (Bryozoa, Gymnolaemata, Ctenostomata) with phylogenetic consideration of Bryozoa. Gene 2009, 439:17-24.

23. Sun M, Shen X, Liu H, Liu X, Wu Z, Liu B: Complete mitochondrial genome of Tubulipora flabellaris (Bryozoa: Stenolaemata): the first representative from the class Stenolaemata with unique gene order. Mar Genomics 2011, 4:159-165.

24. Nesnidal MP, Helmkampf M, Bruchhaus I, Hausdorf B: The complete mitochondrial genome of Flustra foliacea (Ectoprocta, Cheilostomata)compositional bias affects phylogenetic analyses of lophotrochozoan relationships. BMC Genomics 2011, 12:572

25. Helmkampf M, Bruchhaus I, Hausdorf B: Multigene analysis of lophophorate and chaetognath phylogenetic relationships. Mol Phylogenet Evol 2008, 46:206-214

26. Paps J, Baguñà J, Riutort M: Bilaterian phylogeny: a broad sampling of 13 nuclear genes provides a new Lophotrochozoa phylogeny and supports a paraphyletic basal Acoelomorpha. Mol Biol Evol 2009, 26:2397-2406

27. Hausdorf B, Helmkampf M, Meyer A, Witek A, Herlyn H, Bruchhaus I, Hankeln T, Struck TH, Lieb B: Spiralian phylogenomics supports the resurrection of Bryozoa comprising Ectoprocta and Entoprocta. Mol Biol Evol 2007, 24:2723-2729.

28. Hausdorf B, Helmkampf M, Nesnidal M, Bruchhaus I: Phylogenetic relationships within the lophophorate lineages (Ectoprocta, Brachiopoda and Phoronida). Mol Phylogenet Evol 2010, 55:1121-1127.

29. Dunn CW, Hejnol A, Matus DQ, Pang K, Browne WE, Smith SA, Seaver E, Rouse GW, Obst M, Edgecombe GD, Sørensen MV, Haddock SHD, Schmidt-Rhaesa A, Okusu A, Kristensen RM, Wheeler WC, Martindale MQ Giribet G: Broad phylogenomic sampling improves resolution of the animal tree of life. Nature 2008, 452:745-749.

30. Helmkampf M, Bruchhaus I, Hausdorf B: Phylogenomic analyses of lophophorates (brachiopods, phoronids and bryozoans) confirm the Lophotrochozoa concept. Proc R Soc London B 2008, 275:1927-1933.
31. Struck TH, Fisse F: Phylogenetic position of Nemertea derived from phylogenomic data. Mol Biol Evol 2008, 25:728-736.

32. Witek A, Herlyn H, Meyer A, Boell L, Bucher G, Hankeln T: EST based phylogenomics of Syndermata questions monophyly of Eurotatoria. BMC Evol Biol 2008, 8:345

33. Witek A, Herlyn $H$, Ebersberger I, Welch DBM, Hankeln T: Support for the monophyletic origin of Gnathifera from phylogenomics. Mol Phylogenet Evol 2009, 53:1037-1041.

34. Hejnol A, Obst M, Stamatakis A, Ott M, Rouse GW, Edgecombe GD, Martinez P, Baguñà J, Bailly X, Jondelius U, Wiens M, Müller WEG, Seaver E, Wheeler WC Martindale MQ, Giribet G, Dunn CW: Assessing the root of bilaterian animals with scalable phylogenomic methods. Proc R Soc London B 2009, 276:4261-4270.

35. Nesnidal MP, Helmkampf M, Bruchhaus I, Hausdorf B: Compositional heterogeneity and phylogenomic inference of metazoan relationships. Mol Biol Evol 2010, 27:2095-2104.

36. Altenburger A, Wanninger A: Neuromuscular development in Novocrania anomala: evidence for the presence of serotonin and a spiralian-like apical organ in lecithotrophic brachiopod larvae. Evol Dev 2010, 12:16-24.

37. Temereva E, Wanninger A: Development of the nervous system in Phoronopsis harmeri (Lophotrochozoa, Phoronida) reveals both deuterostome- and trochozoan-like features. BMC Evol Biol 2012, 12:121.

38. Cohen BL, Gawthrop A, Cavalier-Smith T: Molecular phylogeny of brachiopods and phoronids based on nuclear-encoded small subunit ribosomal RNA gene sequences. Phil Trans R Soc London B 1998, 353:2039-2061.

39. Zrzavý J, Mihulka S, Kepka P, Bezděk A, Tietz D: Phylogeny of the Metazoa based on morphological and $18 \mathrm{~S}$ ribosomal DNA evidence. Cladistics 1998, 14:249-285.

40. Cohen BL: Monophyly of brachiopods and phoronids: reconciliation of molecular evidence with Linnaean classification (the subphylum Phoroniformea nov.). Proc R Soc London B 2000, 267:225-231.

41. Cohen BL, Weydmann A: Molecular evidence that phoronids are a subtaxon of brachiopods (Brachiopoda: Phoronata) and that genetic divergence of metazoan phyla began long before the early Cambrian. Organ Diver Evol 2005, 5:253-273.

42. Sperling EA, Pisani D, Peterson KJ: Molecular paleobiological insights into the origin of the Brachiopoda. Evol Dev 2011, 13:290-303.

43. Giribet G, Distel DL, Polz M, Sterrer W, Wheeler WC: Triploblastic relationships with emphasis on the acoelomates and the position of Gnathostomulida, Cycliophora, Plathelminthes, and Chaetognatha: a combined approach of $18 \mathrm{~S}$ rDNA sequences and morphology. Syst Biol 2000, 49:539-562.

44. Cohen L: Rerooting the rDNA gene tree reveals phoronids to be 'brachiopods without shells'; dangers of wide taxon samples in metazoan phylogenetics (Phoronida; Brachiopoda). Zool J Linn Soc 2000, 167:82-92.

45. Carlson SJ: Phylogenetic relationships among extant brachiopods. Cladistics 1995, 11:131-197.

46. Williams A, Carlson SJ, Brunton CHC, Holmer LE, Popov L: A supra-ordinal classification of the Brachiopoda. Phil Trans R Soc London B 1996, 351:1171-1193.

47. Nielsen C: Animal evolution: Interrelationships of the living phyla. 2nd edition. Oxford: Oxford University Press; 2001.

48. Giribet G, Dunn CW, Edgecombe GD, Hejnol A, Martindale MQ, Rouse GW: Assembling the spiralian tree of life. In Animal evolution: genes, genomes, fossils and trees. Edited by Telford MJ, Littlewood DTJ. Oxford: Oxford University Press; 2009:52-64.

49. Hejnol A: A twist in time-the evolution of spiral cleavage in the light of animal phylogeny. Integr Comp Biol 2010, 50:695-706.

50. Ebersberger I, de Matos Simoes R, Kupczok A, Gube M, Kothe E, Voigt K, von Haeseler A: A consistent phylogenetic backbone for the fungi. Mol Biol Evol 2012, 29:1319-1334.

51. Jermiin LS, Ho SYW, Ababneh F, Robinson J, Larkum AWD: The biasing effect of compositional heterogeneity on phylogenetic estimates may be underestimated. Syst Biol 2004, 53:638-643.

52. Delsuc $F$, Brinkmann $H$, Philippe $H$ : Phylogenomics and the reconstruction of the tree of life. Nat Rev Genet 2005, 6:361-375.

53. Rodríguez-Ezpeleta N, Brinkmann $\mathrm{H}$, Roure $\mathrm{B}$, Lartillot $\mathrm{N}$, Lang BF, Philippe $\mathrm{H}$ : Detecting and overcoming systematic errors in genome-scale phylogenies. Syst Biol 2007, 56:389-399.

54. Simmons MP: Radical instability and spurious branch support by likelihood when applied to matrices with non-random distributions of missing data. Mol Phylogenet Evol 2012, 62:472-484. 
55. Simmons MP: Misleading results of likelihood-based phylogenetic analyses in the presence of missing data. Cladistics 2012, 28:208-222.

56. Lemmon AR, Brown JM, Stanger-Hall K, Lemmon EM: The effect of ambiguous data on phylogenetic estimates obtained by maximum likelihood and Bayesian inference. Syst Biol 2009, 58:130-145.

57. Jägersten G: Evolution of the metazoan live cycle. London: Academic Press; 1972.

58. Lüter C, Grobe P, Bartolomaeus T: Tentaculata (Lophophorata), Tentakulaten. In Spezielle Zoologie. Teil 1: Einzeller und Wirbellose Tiere. 2nd edition. Edited by Westheide W, Rieger R. München: Elsevier; 2007:764-787.

59. Rattenbury JC: The embryology of Phoronopsis viridis. J Morph 1954, 95:289-340

60. Pennerstorfer $M$, Scholtz G: Early cleavage in Phoronida displays spiral features. Evol Dev 2012, 16:484-500.

61. Temereva EN, Malakhov W: The evidence of metamery in adult brachiopods and phoronids. Invert Zool 2011, 8:87-101.

62. Grobe P: Larval development, the origin of the coelom and the phylogenetic relationships of the Phoronida. PhD thesis: Freie Universität Berlin; 2008.

63. Waeschenbach A, Taylor PD, Littlewood DTJ: A molecular phylogeny of bryozoans. Mol Phylogenet Evol 2012, 62:718-735.

64. Schwaha T, Wanninger A: Myoanatomy and serotonergic nervous system of plumatellid and fredericellid Phylactolaemata (Lophotrochozoa, Ectoprocta). J Morph 2012, 273:57-67.

65. NCBI EST database: [http://www.ncbi.n/m.nih.gov/projects/dbEST].

66. Ebersberger I, Strauss S, von Haeseler A: HaMStR: Profile Hidden markov model based search for orthologs in ESTs. BMC Evol Biol 2009, 9:157.

67. Katoh K, Misawa K, Kuma K, Miyata T: MAFFT: a novel method for rapid multiple sequence alignment based on fast Fourier transform. Nucleic Acids Res 2002, 30:3059-3066.

68. Katoh K, Toh H: Recent developments in the MAFFT multiple sequence alignment program. Brief Bioinform 2008, 9:286-298.

69. Misof B, Misof K: A Monte Carlo approach successfully identifies randomness in multiple sequence alignments: a more objective means of data exclusion. Syst Biol 2009, 58:21-34.

70. Kück P, Meusemann K, Dambach J, Thormann B, von Reumont BM, Wägele JW, Misof B: Parametric and non-parametric masking of randomness in sequence alignments can be improved and leads to better resolved trees. Front Zool 2010, 7:10.

71. ALICUT: [http://www.utilities.zfmk.de]

72. Stamatakis A: RAxML-VI-HPC: maximum likelihood-based phylogenetic analyses with thousands of taxa and mixed models. Bioinformatics 2006, 22:2688-2690

73. Ott M, Zola J, Aluru S, Stamatakis A: Large-scale maximum likelihood-based phylogenetic analysis on the IBM BlueGene/L. In Proceedings of the ACM/IEEE conference on Supercomputing 2007. Reno, Nevada: ACM; 2007.

74. Le SQ, Gascuel O: An improved general amino acid replacement matrix. Mol Biol Evol 2008, 25:1307-1320.

75. Philippe H, Brinkmann H, Lavrov DV, Littlewood DTJ, Manuel M, Wörheide $\mathrm{G}$, Baurain D: Resolving difficult phylogenetic questions: why more sequences are not enough. PLOS Biol 2011, 9:e1000602.

76. Struck TH: The impact of paralogy on phylogenomic studies - a case study on annelid relationships. PLOS ONE 2013, 8:e62892.

77. Tamura K, Peterson D, Peterson N, Stecher G, Nei M, Kumar S: MEGA5: Molecular Evolutionary Genetics Analysis using maximum likelihood, evolutionary distance, and maximum parsimony methods. Mol Biol Evol 2011, 28:2731-2739

78. TreeBASE: [http://www.treebase.org]

79. Lartillot N, Philippe $\mathrm{H}$ : A Bayesian mixture model for across-site heterogeneities in the amino-acid replacement process. Mol Biol Evol 2004, 21:1095-1109.

80. Lartillot N, Rodrigue N, Stubbs D, Richer J: PhyloBayes MPI. Phylogenetic reconstruction with infinite mixtures of profiles in parallel environment. Syst Biol 2013, 62:611-615.

81. Stamatakis A, Hoover $\mathrm{P}$, Rougemont J: A rapid bootstrap algorithm for the RAxML Web servers. Syst Biol 2008, 57:758-771.

82. Pattengale ND, Alipour M, Bininda-Emonds ORP, Moret BME, Stamatakis A How many bootstrap replicates are necessary? J Comput Biol 2010 17:337-354

83. Roure $B$, Baurain D, Philippe $H$ : Impact of missing data on phylogenies inferred from empirical phylogenomic datasets. Mol Biol Evol 2013, 30:197-214
84. Swofford DL: PAUP*. Phylogenetic Analysis Using Parsimony * and other methods. Version 4.0610. Sinauer Associates.: Sunderland MA; 2002.

85. Kück P, Struck TH: BaCoCa-A heuristic software tool for the parallel assessment of sequence biases in hundreds of gene and taxon partitions. Mol Phylogenet Evol 2014, 70:94-98

86. Hammer $\varnothing$. Harper DAT, Ryan PD: PAST: paleontological statistics software package for education and data analysis. Palaeontol Electr 2001, 4:9.

87. Schmidt HA, Strimmer $K$, Vingron $M$, von Haeseler A: TREE-PUZZLE: maximum likelihood phylogenetic analysis using quartets and parallel computing. Bioinformatics 2002, 18:502-504.

doi:10.1186/1471-2148-13-253

Cite this article as: Nesnidal et al:: New phylogenomic data support the monophyly of Lophophorata and an Ectoproct-Phoronid clade and indicate that Polyzoa and Kryptrochozoa are caused by systematic bias. BMC Evolutionary Biology 2013 13:253.

\section{Submit your next manuscript to BioMed Central and take full advantage of:}

- Convenient online submission

- Thorough peer review

- No space constraints or color figure charges

- Immediate publication on acceptance

- Inclusion in PubMed, CAS, Scopus and Google Scholar

- Research which is freely available for redistribution 